\title{
Multiphase Flow Regularity of Wellbore in Acid Natural Gas-invading Period
}

\author{
Zhaokai Hou ${ }^{1}$, Tie Yan ${ }^{1}$, Shihui Sun ${ }^{1 *}$,Yuan Yuan ${ }^{2}$ and Jingze Liu ${ }^{3}$ \\ ${ }^{1}$ Petroleum Engineering College, Northeast Petroleum, Daqing, Heilongjiang 163318, China \\ ${ }^{2}$ The Experimental Group of NO.1 Production Plant, Daqing, Heilongjiang 163000, China \\ ${ }^{3}$ Daqing Oil Filed Co., Ltd. of PetroChina, Daqing, Heilongjiang 163453, China
}

Received 22 March 2017; Accepted 11 July 2017

\begin{abstract}
Currently, unbalanced drilling technique is widely applied in the exploration and development process of acid oil and gas reservoir. However, the acid natural gas that invades under high-temperature and high-pressure conditions can easily result in underground failures, such as well kick and blowout. Thus, a calculation model for the multiphase flow of a wellbore that is invaded by acid natural gas was established in this study based on the principle and method of gas-liquid two-phase flow to reveal the multiphase flow regularity inside a wellbore after the invasion of acid natural gas, considering the phase change and solubility of acid gas under high temperature and high pressure. Meanwhile, a solution for the model was provided. Finally, in the case of the H75-29-9 gas well conditions in Jilin Oilfield, China, the change rule of physical properties and the change features of parameters, such as mud pit increment and pressure drop in the bottom hole after acid natural gas (methane and hydrogen sulfide) penetrated the wellbore, were obtained through an analog calculation. Results indicate that the $\mathrm{H}_{2} \mathrm{~S}$ solubility inside the wellbore is greater than the $\mathrm{CH}_{4}$ solubility. Moreover, $\mathrm{H}_{2} \mathrm{~S}$ is 135 times more soluble than $\mathrm{CH}_{4}$ in the bottom hole. The density of acid natural gas mutates near the wellhead. High $\mathrm{H}_{2} \mathrm{~S}$ content implies that the mutation location is near the wellhead. The density mutation location of pure $\mathrm{H}_{2} \mathrm{~S}$ mutates $400 \mathrm{~m}$ away from the wellhead, whereas the density of a $50 \% \mathrm{H}_{2} \mathrm{~S}$ mutates $900 \mathrm{~m}$ away from the wellhead. Within the same overflow period, a high $\mathrm{H}_{2} \mathrm{~S}$ content implies a small pressure drop value in the bottom hole, mud pit increment, and shut-in casing pressure, and small volume fractions of gaseous phases at the wellhead and in the center of the wellbore. Backpressure and the gas-invaded quantity at the wellhead have great influences on pressure in the bottom hole, that is, a great backpressure at the wellhead implies a low pressure drop in the bottom hole. Moreover, less gasinvaded flow quantity implies a small pressure drop in the bottom hole. This study provides a theoretical basis for wellbore pressure control and well-killing construction under complicated conditions.
\end{abstract}

Keywords: Unbalanced Drilling, Acid Natural Gas, Phase Change, Solubility

\section{Introduction}

Unbalanced drilling(UBD) is a drilling technique in which formation fluid controllably enters a wellbore and circulates in the ground when the bottom hole pressure is lower than the formation pressure during the drilling process. UBD has become popular in the development of drilling techniques following horizontal well technique because of its technical advantages, such as high penetration rate, effective control of leakage zone, real-time finding of abnormal geological conditions, timely evaluation of low-pressure and lowpermeability hydrocarbon reservoir, and protection of hydrocarbon reservoir. Moreover, UBD has its own advantages in developing acid oil and gas field with extensive application prospects in China[1].

Unbalanced drilling technique results in oil and gas yield increase. However, the thermodynamic and hydrodynamic balances of acid natural gas that enter the wellbore because of unbalanced conditions can change under high-temperature and high-pressure environments. Consequently, the gas dissolved in the drilling fluid is

\footnotetext{
*E-mail address: hzk786@126.com

ISSN: 1791-2377 @ 2017 Eastern Macedonia and Thrace Institute of Technology. All rights reserved.

doi:10.25103/jestr.103.20
}

released, and phase change between gas and liquid occurs because natural gas can be condensed into oil. Phase change can change the proportions and properties of liquid and gas in the well, thereby changing the flow pattern of the circulating fluid. Therefore, acid gas invasion can complicate the multiphase flow in the wellbore, thus influencing well control significantly.

On this basis, researchers have conducted numerous studies on multiphase flow regularity in the wellbore after natural gas invasion [2-6]. However, an accurate analysis of the multiphase flow regularity in the wellbore after the invasion of acid natural gas under high-temperature and high-pressure conditions and the definition of the main factors that influence multiphase flow during unbalanced drilling process are required. This is because the assumptions in these studies are too simple and do not consider the influences of factors, such as the subsistent solubility and gas-liquid phase change of acid gas on multiphase flow inside the wellbore under high-temperature and high-pressure environments, and the existence of great deviations when these studies are applied to unbalanced drilling under high-temperature and high-pressure environments, which can influence the construction safety of unbalanced drilling and result in serious consequences and heavy economic losses. 
For acid natural gas reservoir features and in consideration of the influences of the dissolution and gasliquid phase change of natural gas, a multiphase flow calculation model was established in this study for the wellbore after acid natural gas invasion under hightemperature and high-pressure conditions. Moreover, factors, such as gaseous phases volume fraction, solubility, and bottom hole pressure, were analyzed to predict the multiphase flow regularity inside the wellbore accurately after the invasion of acid natural gas to provide reference for the development and optimization of acid gas reservoirs.

\section{State of the art}

Researchers have conducted numerous studies on gas-liquid two-phase flow after gas invasion [7-14]. Sheldon et al. [15] set up the first simple gas invaded mathematical model that belongs to the current-sharing model. However, the flow friction resistance of the drilling fluid in annuli and the slippage of gas-invaded gas in the drilling fluid are neglected. Auton [16] improved the model of Sheldon [15] and proposed a new well kick flow model that considers the flow friction resistance of the drilling fluid in annuli. This model provides high calculation accuracy but the calculation method of flow inside the drill pipe is not provided. Horberock et al. [17-18] imported a momentum equation to calculate the annular pressure. However, this model ignores the change of annular sectional area during the flow process and simplifies the two-phase flow into a single-phase flow. Nickens [19] established a gas-liquid two-phase continuity equation and a mixing momentum equation and presented a mathematical method that uses fixed grids in the numerical solution by analyzing the changes of mass and mixing momentum during the gas-liquid two-phase flow process. However, this model uses static temperature field and does not consider the dissolution effect of gas in the drilling fluid. Jun Fan et al. [20] built a gas-liquid two-phase flow model based on the multiphase transient flow theory inside the wellbore and simulated the change of bottom hole pressure with time and multiphase flow parameters of the wellbore with well depth at different gas injection rates. Moreover, this model has poor applicability in deepwater and ultradeepwater vertical wellbores. Shi et al. [21] established a gas-liquid and an oil-water two-phase drift flow models, considering interphase slippage. The model prediction results are consistent with the experimental results. Moreover, the prediction error of the void ratio was within $\pm 20 \%$, but the results were not compared. Hagedorn and Brown [22] conducted an indoor experiment on a two-phase flow in round pipes. The diameters of the round pipes used in the experiment were 25,32 , and $38 \mathrm{~mm}$. The pressure drop gradients of the two-phase flow were tested under different liquid and gas injection volumes. The calculation results in this empirical formula were always smaller than the field measurement results.

The studies above focused on the two-phase flow of conventional single-phase drilling fluid in deep wells. Studies on the multi-phase flow of a wellbore under hightemperature and high-pressure status, as well as studies on the dissolution properties and phase-state change of acid gas, were few. The multiphase mathematical model of the well during acid gas-invasion period were established in this study that contained the gas-liquid two-phase continuity equation and gas-liquid two-phase mixing motion equation which based on the principles of mass and momentum conservation and based on the influences of gas solubility and phase change. Meanwhile, the calculation model of gas solubility, the flash evaporation and classical pressure drop model of the two-phase pipe flow were established. The change rules of the parameters, such as gas solubility, annular gas phase volume fraction, mud pit increment, and bottom hole pressure drop were obtained through an analog calculation during acid gas-invasion period. The influencing factors of the multiphase flow regularity of a wellbore during acid gas-invasion period were analyzed to provide a theoretical basis for the design optimization of well control parameters of follow-up deep unbalanced drilling.

The rest of this study is organized as follows. Section 3 establishes the wellbore multiphase calculation model during the acid natural gas-invasion period and provides a solution of finite difference method. Section 4 simulates the change features of gas-liquid two-phase flow parameters in the wellbore during the acid gas-invasion process and analyzes the influencing factors of the multiphase flow regularity of a wellbore during the gas-invasion period. Section 5 summarizes the whole study and draws relevant conclusions.

\section{Methodology}

\subsection{Multiphase flow equation of a wellbore}

\subsubsection{Fluid continuity equation of a wellbore during the acid natural gas-invasion period}

The generation of formation gas and the dissolution of gas in the drilling fluid should be considered in the continuity equation during the gas-invasion period in unbalanced drilling. Thus, this continuity equation is relatively complicated. The derivation with gaseous pay zone segment can be taken as an example.

The free phase of acid gas can be written as

$$
\frac{\partial}{\partial t}\left(\rho_{g} H_{g} A\right)+\frac{\partial}{\partial z}\left(\rho_{g} v_{g} H_{g} A\right)=q_{g}-q_{s}+x_{s}
$$

The dissolution phase of invading acid gas can be written as

$$
\frac{\partial}{\partial t}\left(\rho_{s} H_{s} A\right)+\frac{\partial}{\partial z}\left(\rho_{s} v_{s} H_{s} A\right)=q_{s}-x_{s}
$$

The drilling fluid phase can be written as

$$
\frac{\partial}{\partial t}\left(\rho_{m} H_{m} A\right)+\frac{\partial}{\partial z}\left(\rho_{m} v_{m} H_{m} A\right)=0
$$

where $z$ is wellbore length, m. $t$ is the time of the fluid invading wellbore, s. $A$ is annular sectional area, $\mathrm{m}^{3} . H_{g}$ is volume fraction of the invading free phase of the fluid . $H_{s}$ is volume fraction of the invading dissolution phase of the fluid. $H_{m}$ is volume fraction of the drilling phase of the fluid. $v_{g}$ is velocity of the invading free phase of the fluid, $m / s . v_{s}$ is velocity of the invading dissolution phase of the fluid, $m / s . v_{m}$ is velocity of the drilling phase of the fluid, $m / s . \rho_{g}$ is density of the invading free phase of the fluid, $\mathrm{kg} / \mathrm{m}^{3} \cdot \rho_{s}$ is density of the invading dissolution phase of 
the fluid, $\mathrm{kg} / \mathrm{m}^{3} \cdot \rho_{m}$ is density of the drilling phase of the fluid, $\mathrm{kg} / \mathrm{m}^{3} \cdot q_{g}$ is total mass flow of the invading fluid, $\mathrm{kg} / \mathrm{s} . q_{s}$ is mass flow dissolved in acid natural gas in the water-based drilling fluid, $\mathrm{kg} / \mathrm{s} . \mathrm{x}_{\mathrm{s}}$ is mass flow of acid natural gas precipitated out from the water-based drilling fluid, $\mathrm{kg} / \mathrm{s}$.

\subsubsection{Momentum conservation equation}

The unified momentum equation of dissolved gas, free gas, and drilling fluid in bottom hole are as follows:

$$
\begin{aligned}
& \frac{\partial}{\partial z}\left(\rho_{m} v_{m}^{2} H_{m} A+\rho_{g} v_{g}^{2} H_{g} A+\rho_{s} v_{s}^{2} H_{s} A\right)+ \\
& \frac{\partial}{\partial t}\left(\rho_{m} v_{m} H_{m} A+\rho_{g} v_{g} H_{g} A+\rho_{s} v_{s} H_{s} A\right) \\
& =-A \frac{\partial p}{\partial z}-A\left(\rho_{g} H_{g}+\rho_{m} H_{m}+\rho_{s} H_{s}\right) g-A\left(\frac{\partial p}{\partial z}\right)_{f r}
\end{aligned}
$$

where $g$ is the gravitational acceleration, $m / s^{2} . P$ is the pressure, $\mathrm{Pa}$, and $f_{r}$ is the frictional pressure drop along the flow direction, $\mathrm{Pa}$.

\subsubsection{Discrimination of the two-phase flow pattern in the annuli and pressure drop calculation}

The pressure drop gradient calculation of the two-phase flow pattern may refer to the models of Hasan and Kabir [3-5]. Hasan and Kabir divided the flow pattern of the gas-liquid phase into four types, namely, bubble flow, slug flow, stirring flow, and annular flow according to the distribution shape of the gas-liquid two-phase medium.

Chen proposed an explicit calculation mode of friction coefficient, which was used for Fanning friction coefficients of bubble flow, slug flow, and stirring flow models of the annular gas-liquid mixture, in 1979. The calculation mode of this friction coefficient is applicable to all Reynolds numbers and roughness.

\subsection{Calculation model of gas-liquid two-phase equilibrium}

Phase equilibrium operation is needed for the judgment of the fluid phase state. Fluid phase equilibrium model consists of three parts, including the equation set of the material equilibrium conditions that describes the relationships of the gas-liquid phase composition, material mass (mole number), and equilibrium constant with temperature and pressure, the equation set of thermodynamic equilibrium conditions that describes the relationships of the gas-liquid phase composition, material mass, and equilibrium constant with fugacity, and the structural system of the state equation used for phase equilibrium calculation.

\subsubsection{Equation set of material equilibrium}

Oil and gas hydrocarbon system consists of $\mathrm{n}$ components, its total material mass is $1 \mathrm{~mol}$, and a normalized condition of the mass number is achieved when the system is under the gas-liquid two-phase equilibrium:

$$
V+L=1
$$

The balancing components in the gas and liquid phases achieve a material equilibrium relationship:
$V y_{i}+L x_{i}=1$

Compositions, such as $y_{1}, y_{2} \ldots \ldots y_{n}$ and $x_{1}, x_{2} \ldots \ldots x_{n}$, should achieve normalized conditions:

$$
\sum_{i=1}^{n} y_{i}=1
$$

$$
\sum_{i=1}^{n} x_{i}=1
$$

The distribution ratio of any component in a balanced gas-liquid phase can be described by the equilibrium constant $K_{i}$, which is equal to the ratio of the mole fraction $y_{i}$ of this component in the gas phase and to the mole fraction $x_{i}$ in the liquid phase under the phase equilibrium condition, that is

$K_{i}=\frac{y_{i}}{x_{i}}$

Where $L$ is the total number of mole in the liquid phase, mol. $V$ is total number of mole in the gas phase, mol. $x_{i}$ is the molar composition of component $i$ in the liquid phase, $y_{i}$ is the molar composition of component $i$ in the gas phase, $K_{i}$ is the equilibrium constant.

\subsubsection{Equation set of the thermodynamic equilibrium} Phase equilibrium calculation cannot be completely realized by the establishment of an equation set of material equilibrium. The distribution proportion constant, namely, the equilibrium constant $K_{i}$ of each component, should be accurately determined after the gas and liquid phases reach phase equilibrium. According to equilibrium theory of fluid thermodynamics, when the oil and gas hydrocarbon system reaches gas-liquid phase equilibrium, the fugacity $f_{i g}$ and $f_{i l}$ of each component in the gas and liquid phases in the system should satisfy

$$
f_{\text {ig }}=f_{\text {il }}
$$

The fugacity of the gas and liquid phases in the system is

$$
f_{i g}=y_{i} \varphi_{i g} p
$$

and

$$
f_{\text {ig }}=x_{i} \varphi_{i l} p
$$

The equilibrium coefficient $K$ is

$$
K_{i}=\frac{y_{i}}{x_{i}}=\frac{\varphi_{i l}}{\varphi_{i g}} \frac{\frac{f_{i l}}{x_{i}}}{\frac{f_{i g}}{y_{i}}}
$$

Where $\varphi_{i g}$ and $\varphi_{i l}$ are the fugacity coefficients of components in a balanced gas-liquid phase. $f_{i g}$ and $f_{i l}$ are 
the fugacity of each component in the gas and liquid phases, $\mathrm{Pa}$.

\subsubsection{State equation of gas}

State equation of gas is used as an acid natural gas calculation model involved in this study. Strict integral equations to solve $\varphi_{i g}$ and $\varphi_{i g}$ using the thermodynamic theory of the phase equilibrium can be written as

$$
\begin{aligned}
& R T \ln \left(\frac{f_{i g}}{y_{i} p}\right)=\ln \varphi_{i g}=\int_{V_{g}}^{\infty}\left[\left(\frac{\partial p}{\partial y_{i g}}\right)_{V_{g} T_{z_{i g}}}-\frac{R T}{V_{g}}\right] d V_{g}-R T \ln Z_{g} \\
& R T \ln \left(\frac{f_{i l}}{x_{i} p}\right)=\ln \varphi_{i l}=\int_{V_{l}}^{\infty}\left[\left(\frac{\partial p}{\partial x_{i l}}\right)_{V_{I} T_{z_{i l}}}-\frac{R T}{V_{l}}\right] d V_{l}-R T \ln Z_{l}
\end{aligned}
$$

The definition of the combined gas-liquid equilibrium constant and the calculation model of the gas-liquid phase flash evaporation can be derived through the simultaneous solution of the equilibrium relationships.

The equation set of gaseous material equilibrium is as follows:

$$
\sum_{i=1}^{n} y_{i}=\sum_{i=1}^{n} \frac{z_{i} K_{i}}{1+\left(K_{i}-1\right) V}=1
$$

and the equation set of the liquid-phase material equilibrium is

$$
\sum_{i=1}^{n} x_{i}=\sum_{i=1}^{n} \frac{z_{i}}{1+\left(K_{i}-1\right) V}=1
$$

where $Z_{i}$ is the molar composition of component $i$ in the hydrocarbon mixing system, $Z_{g}$ and $Z_{l}$ are deviation factor of liquid-phase and gaseous in the hydrocarbon mixing system, $p$ is the pressure of the hydrocarbon system, Pa. $T$ is the temperature of the hydrocarbon system, $\mathrm{K}, R$ is gas constant, $\mathrm{J} /(\mathrm{mol} \cdot \mathrm{K}), V_{l}$ and $V_{g}$ are the volume of liquidphase and gaseous in the hydrocarbon mixing system, $m^{3}, Z_{i l}$ is the mole fraction of component $i$ in the liquid phase. $Z_{i g}$ is the mole fraction of mole in the gas phase.

The aforementioned gas-liquid phase equilibrium equations are combined with the thermodynamic conditions of the fugacity equilibrium. Then, the calculation of the gasliquid phase equilibrium can be implemented by using dew point, bubble point, critical point, iso-liquid volume line, critical condensation pressure, or critical condensation temperature.

\subsection{Calculation of the physical property parameters of acid natural gas and drilling fluid}

\subsubsection{Solubility model}

The comparatively new model that calculates the solubility of acid gas in water within global and domestic scopes at present is based on the Duan state equation established by nodes, whereas the time domain consists of the entire time quantum from the initial calculation to the calculation completion. Leading edge tracking multiphase flow is adopted for the selection of time grids. Time step is calculated according to the increase of gas velocity and space grid length at this location. The heat of the wellbore
Zhenhao Duan [23-25]. This model has high accuracy in calculating the solubility of acid gas in a wellbore during the drilling process, and its deviation does not exceed $6 \%$.

\subsubsection{Calculation of critical temperature and critical pressure}

The critical temperature and the critical pressure of an acid fluid must be determined considering the phase change of acid fluid. Pseudo-critical parameters are used as critical parameters of natural gas. Kay's mixing rule is usually adopted and its definition is

$$
P_{P C}=\sum_{i=1}^{n} y_{i} p_{c i}
$$

and

$$
T_{P C}=\sum_{i=1}^{n} y_{i} T_{c i}
$$

Where $P_{p c}$ is the pseudo-critical pressure, $\mathrm{Pa}, T_{p c}$ is the pseudo-critical temperature of the mixture, K. $P_{c i}$ and the critical pressure of component $i, \mathrm{~Pa}, T_{c i}$ is the critical temperature of component $i, \mathrm{~K}$.

\subsubsection{Calculation of compressibility factor}

PR equation is selected in this study as a state equation. However, the calculation of compressibility factor in PR equation cannot comply with the calculation requirement in this study, and thus, re-consideration is needed. The following method is used in this study:

$$
Z=L \times Z_{l}+V \times Z_{g}
$$

\subsubsection{Density calculation}

According to the state equation of actual gas, acid natural gas density is obtained:

$$
\rho=p M / Z R T
$$

Where $M$ is the molar mass of the gas, $\mathrm{g} / \mathrm{mol}$.

\subsubsection{Viscosity calculation model}

Temperature and pressure ranges involved in this study belong to high temperature and high pressure. Gas viscosity calculation model called Chung model is commonly used at home and abroad as a viscosity calculation model under high temperature and high pressure. 3.5 Local search operation

\subsection{Solution of equation set}

The analytical solution of the multiphase flow control equation is difficult to solve. Thus, a discrete nominalization processing of the model should be implemented, and finite difference method is used for solving the solution. The spatial domain consists of the whole drill stem and annular

should be transferred to each grid, except for space and time grids, for iterative solution under transient flow. Finite difference method is used to discretize the mathematical model. The solution of the original mathematical model in the definite solution domain is transformed into a discrete solution on grid nodes in the definite solution domain to 
solve the solutions of the nodes in the space domain hour by hour and step by step until the whole time domain is covered, and then the solution of the corresponding problem can be obtained. Fig. 1 shows the concrete solution.

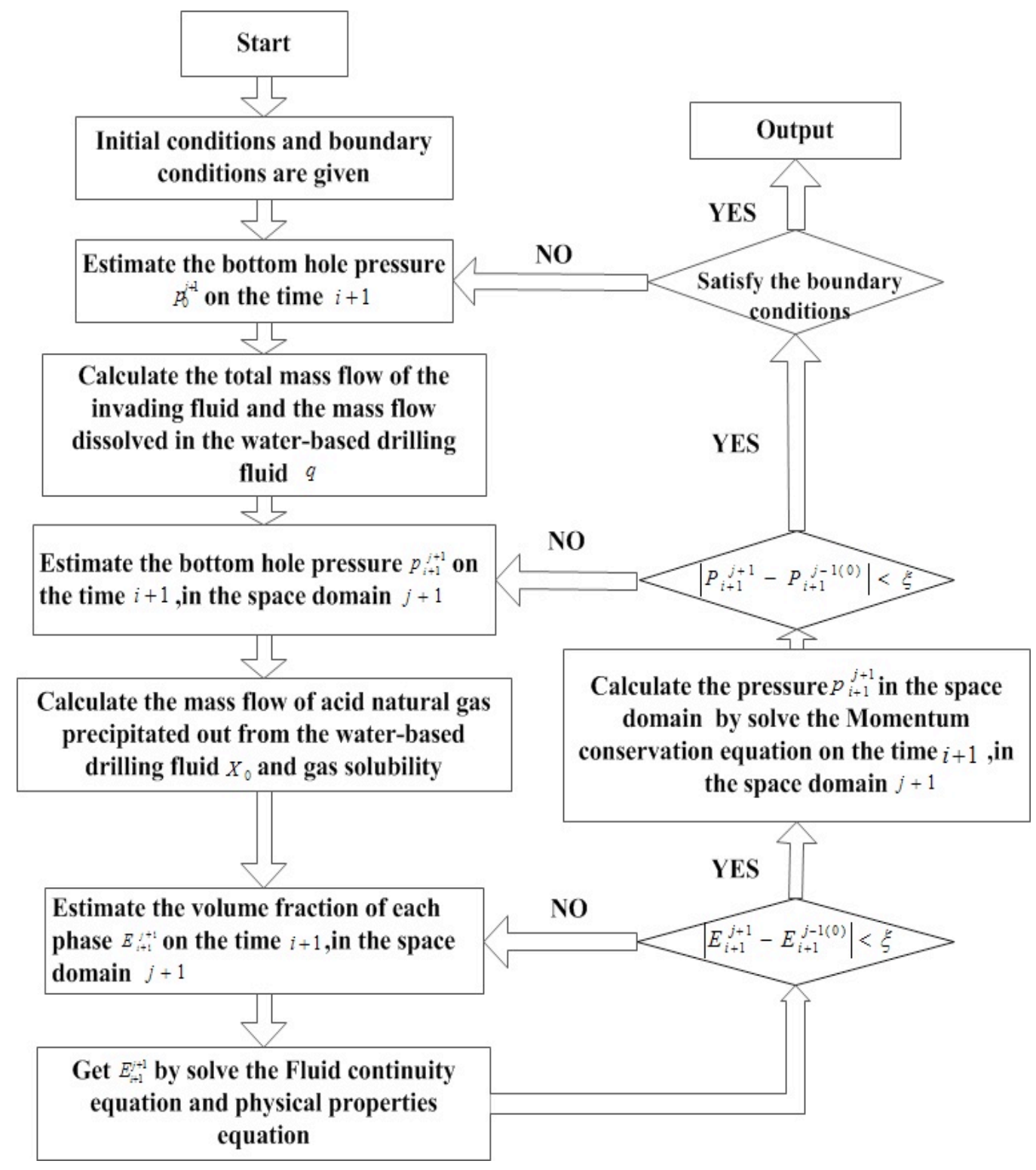

Fig. 1. Solving Process of a Wellbore Flow Model

\section{Results and discussion}

The basic data of gas well with high $\mathrm{H}_{2} \mathrm{~S}$ content in Jilin Oilfield H75-29-9 China were used to simulate the flow characteristics inside a wellbore under high $\mathrm{H}_{2} \mathrm{~S}$ gasinvasion. Fig. 2 shows the construction site. The designed depth and vertical depth of the well were 4.289 and $3.410 \mathrm{~km}$, respectively. The well was drilled to a depth of $4.04968 \mathrm{~km}$ and a vertical depth of $3.381 \mathrm{~km}$. A $244.5-\mathrm{mm}$ casing pipe was delivered $2.479 \mathrm{~km}$ below the well. Furthermore, drills with $215.9 \mathrm{~mm}$ outer diameter were used. The deviation of the well, the density of the drilling fluid, and the $\mathrm{H}_{2} \mathrm{~S}$ content were $82^{\circ}, 1.43 \mathrm{~g} / \mathrm{m}^{3}$, and $151 \mathrm{~g} / \mathrm{cm}^{3}$, respectively. During the calculation process, the formation pressure coefficient, surface temperature, geothermal gradient, initial drilling velocity, gas-invaded flow velocity, plastic viscosity, and tangential dynamic stress were set to $1.5,30^{\circ} \mathrm{C}, 3^{\circ} \mathrm{C} / 100 \mathrm{~m}$, $0.08 \mathrm{~m} / \mathrm{s}, 0.8 \mathrm{~m}^{3} / \mathrm{s}, 0.03 \mathrm{~Pa} \cdot \mathrm{S}$ and $1.5 \mathrm{~Pa}$, respectively.

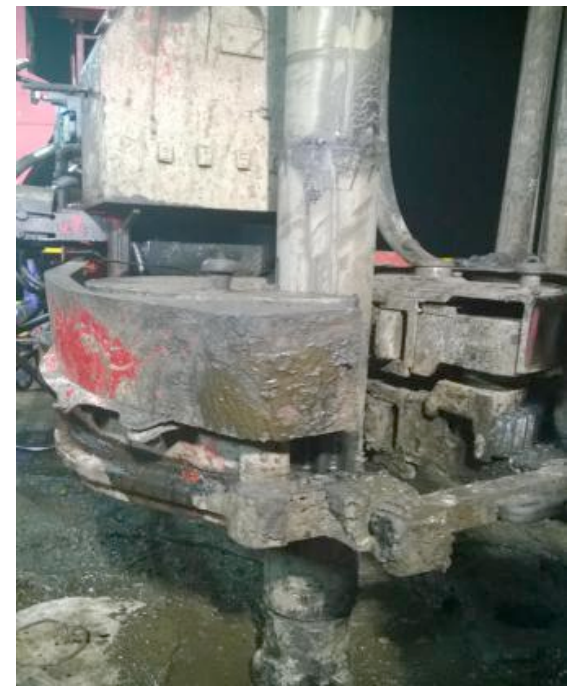

Fig. 2. Construction on Drilling Site 


\subsection{Change of $\mathrm{H}_{2} \mathrm{~S}$ solubility with well depth}

Fig. 3 shows the change curve of gas solubility with well depth. The solubility of $\mathrm{H}_{2} \mathrm{~S}$ and $\mathrm{CH}_{4}$ increased with the depth of the well. The change of $\mathrm{CH}_{4}$ solubility was relatively gentle, and its solubility was almost zero under a wellhead condition and was approximately 0.00105 under the bottom hole condition. The solubility of $\mathrm{H}_{2} \mathrm{~S}$ at the wellhead was also almost zero, however, it began to rapidly increase rapidly at approximately $400 \mathrm{~m}$ away from the wellhead. Finally, its solubility was 135 times more that the solubility of $\mathrm{CH}_{4}$ in the bottom hole because as the well depth increased, the temperature and pressure inside the wellbore also increased. When the well depth reached $400 \mathrm{~m}$, the temperature reached its critical point, thus, the hydrogen sulfide went through phase change, that is, the hydrogen sulfide transformed from gaseous state into supercritical state in which a supercritical fluid has strong solubility.

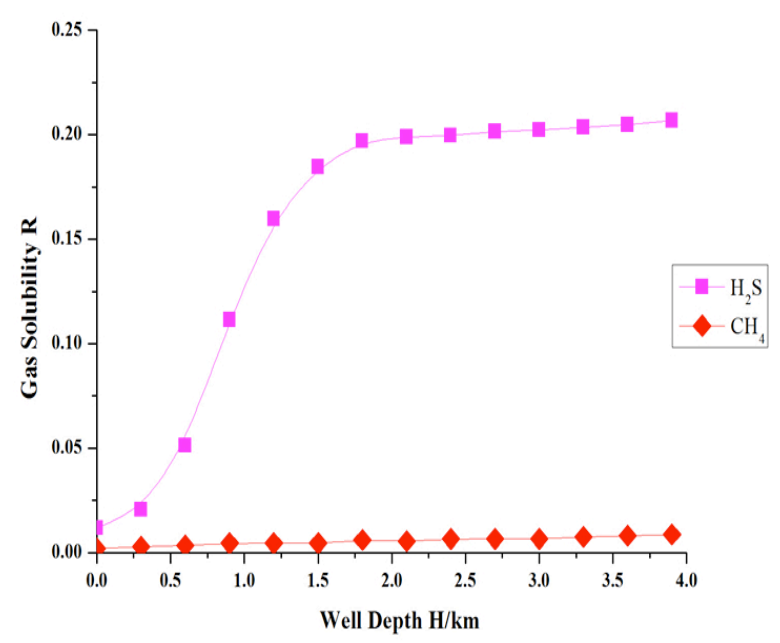

Fig. 3. Change Curve of Gas Solubility

\subsection{Change Curves of Gas Densities}

Fig. 4 shows the change curves of gas density with well depth under different $\mathrm{H}_{2} \mathrm{~S}$ contents. The change amplitude of methane density with well depth was low. However, the change amplitude of acid natural gas was great. The acid natural gases of different contents near the wellhead would experience an abrupt enlargement process. A high $\mathrm{H}_{2} \mathrm{~S}$ content results in a closer mutation point to the wellhead. The density of $50 \% \mathrm{H}_{2} \mathrm{~S}$ gas began to increase rapidly at $0.9 \mathrm{~km}$ or higher, and the location, in which $100 \%$ $\mathrm{H}_{2} \mathrm{~S}$ started to rapidly increase, was $400 \mathrm{~m}$ away from the wellhead, which might be caused by the phase change of $\mathrm{H}_{2} \mathrm{~S}$ during the process of increasing along the wellbore.

$\mathrm{H}_{2} \mathrm{~S}$ was under a supercritical state in the bottom hole, and its density was approximate to its liquid-phase density. $\mathrm{H}_{2} \mathrm{~S}$ was transformed from a supercritical state into gaseous state when it was close to the wellhead, and its density rapidly reduced and its volume rapidly expanded.

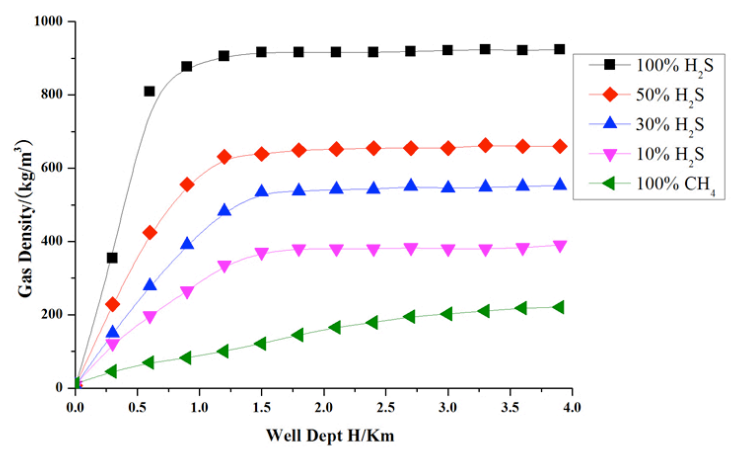

Fig. 4. Change Curves of Gas Densities

\subsection{Change of bottom hole pressure during overflow process of gas well with high $\mathrm{H}_{2} \mathrm{~S}$ content}

Fig. 5 shows the change curves of the bottom hole pressure with overflow time under different $\mathrm{H}_{2} \mathrm{~S}$ contents. The bottom hole pressure gradually declined as the overflow time increased. At the initial gas-invaded period, the bottom hole pressure declined slowly with nearly consistent declining rate. When the gas-invaded gas was pure $\mathrm{CH}_{4}$, the decline amplitude of the bottom hole pressure with overflow time was the greatest. However, as the $\mathrm{H}_{2} \mathrm{~S}$ content in the gas-invaded increased, the decline amplitude of bottom hole pressure became slow because the $\mathrm{H}_{2} \mathrm{~S}$ solubility was far stronger than the $\mathrm{CH}_{4}$ solubility. Under the same gasinvaded amount, high $\mathrm{H}_{2} \mathrm{~S}$ content results in more $\mathrm{H}_{2} \mathrm{~S}$ dissolved in the drilling fluid and reduced number of free gases in the drilling fluid. Meanwhile, the density of $\mathrm{H}_{2} \mathrm{~S}$ was greater than the density of $\mathrm{CH} 4$ density. Therefore, high $\mathrm{H}_{2} \mathrm{~S}$ content in gas-invaded gas results in slower bottom hole pressure drop.

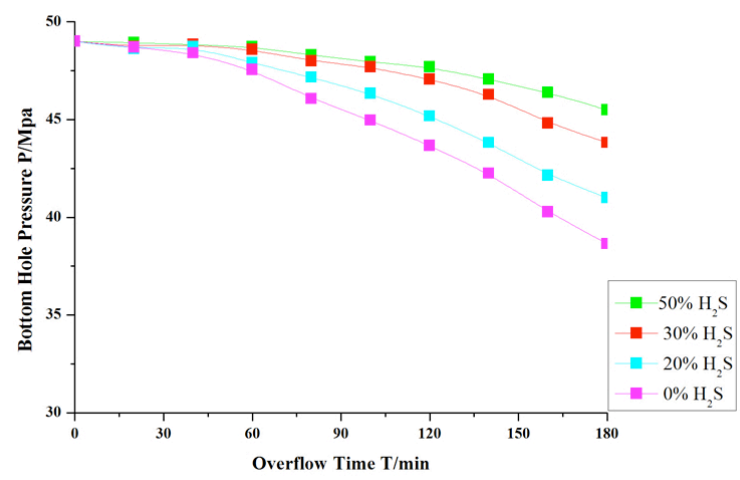

Fig. 5. Change Curves of Bottom Hole Pressure with Overflow Time

4.4 Change of Gas Phase Volume Fractions during the increasing process of high $H_{2} S$ content gas along the wellbore

Fig. 6 shows the gas phase volume fraction distribution when the gas increased along the wellbore to the center of the wellbore under different $H_{2} S$ contents. The volume fraction of the methane was greater than the $\mathrm{H}_{2} \mathrm{~S}$ containing acid gas because when the gas invaded center of the wellbore, the bottom hole pressure was still high, the $\mathrm{H}_{2} \mathrm{~S}$ was under a supercritical state, and the solubility and 
density of $\mathrm{H}_{2} \mathrm{~S}$ were great under low invasion velocity. Thus, ordinary natural gas had greater volume fraction than free gas in acid gas.

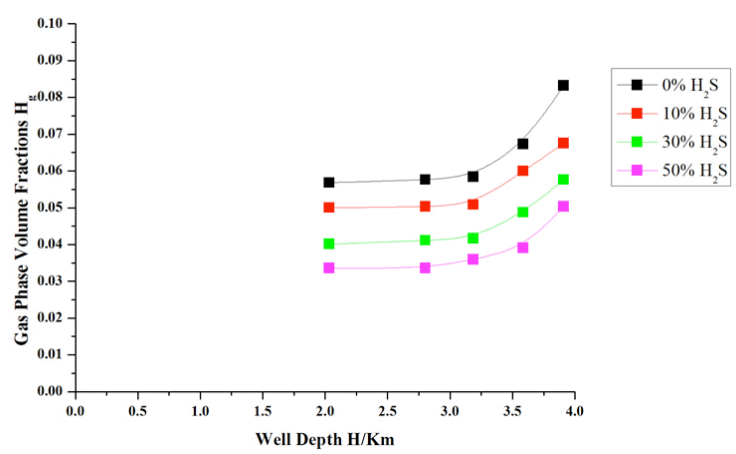

Fig. 6. Gas Phase Volume Fractions in the wellbore when the Gas Rises to Its Middle Position

Fig. 7 shows gas phase volume fraction distribution when ordinary natural gas and acid gas overflew towards the wellhead. When the gas overflow toward the wellhead, the gas phase volume fraction at the wellhead was far greater than that at the bottom hole when it overflew toward the center of the wellbore because when temperature and pressure decreased, the gas volume abruptly expanded, and the volume fraction of free gas at the wellhead rapidly increased.

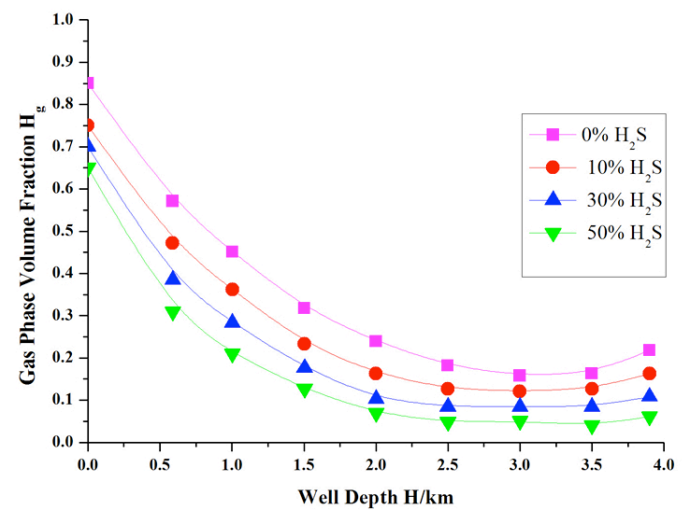

Fig. 7. Gas Phase Volume Fraction in the Wellbore when the Gas Rises to Wellhead

\subsection{Change of mud pit increment in high $\mathrm{H}_{2} \mathrm{~S}$ content} gas well with overflow time

Fig. 8 shows the change curves of mud pit increment with overflow time under different $\mathrm{H}_{2} \mathrm{~S}$ contents. As the overflow time increased, the mud pit increment presented an approximately exponential increase. Under the same initial conditions and within the same overflow time, high $\mathrm{H}_{2} \mathrm{~S}$ content results in smaller mud pit increment. At $90 \mathrm{~min}$ overflow time, the mud pit increment caused by gas with $50 \% \mathrm{H}_{2} \mathrm{~S}$ content was $9 \mathrm{~m}^{3}$ smaller than that caused by $0 \%$ $\mathrm{H}_{2} \mathrm{~S}$ gas because $\mathrm{H}_{2} \mathrm{~S}$ was under a supercritical state and was mutually dissolved with the drilling fluid before reaching the wellhead. Moreover, high $\mathrm{H}_{2} \mathrm{~S}$ content results in less free gas in the drilling fluid and smaller volume expansion.

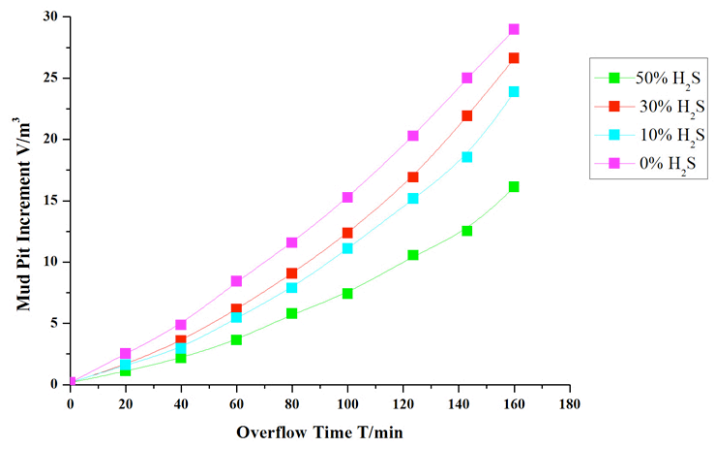

Fig. 8. Change Curves of mud pit Increment with Overflow Time

4.6 Change of shut-in casing pressure during overflow process of high $\mathrm{H}_{2} \mathrm{~S}$ content gas well

Fig. 9 shows the change curves of the shut-in casing pressure with overflow time under different $\mathrm{H}_{2} \mathrm{~S}$ contents. As the overflow progressed, the shut-in casing pressure gradually increased. Consequently, the high $\mathrm{H}_{2} \mathrm{~S}$ content results in low shut-in casing pressure because more gases entered the wellbore as the overflow continued. Thus, the hydrostatic fluid column pressure loss in the annuli would increase. The gas volume in the annuli would decrease because of the solubility of the $\mathrm{H}_{2} \mathrm{~S}$ gas in water. Meanwhile, the density of the gas that contains $\mathrm{H}_{2} \mathrm{~S}$ was high, thus the annular hydrostatic column pressure increases compared to the gas without $\mathrm{H}_{2} \mathrm{~S}$.

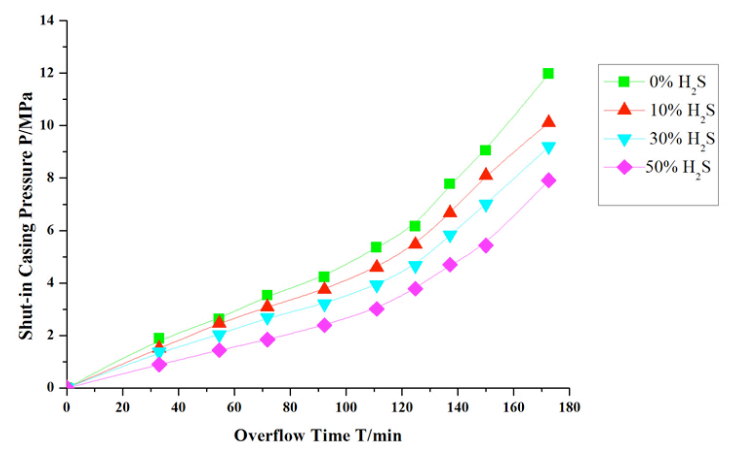

Fig. 9. Change Curves of Shut-in Casing Pressure with Overflow Time

4.7 Change of bottom hole pressure under different gasinvaded velocities

Fig. 10 shows the comparison curves of the change of bottom hole pressure with time under different gas-invaded flow quantities. The gas-invaded flow quantity reflected the gas-invasion severity. It affects the bottom hole pressure significantly. Meanwhile, high gas-invaded quantity results in fast bottom hole pressure drop. More formation fluids flowed into the wellbore with the bottom hole pressure drop, resulting in a continuous bottom hole pressure drop, which is repeated. 


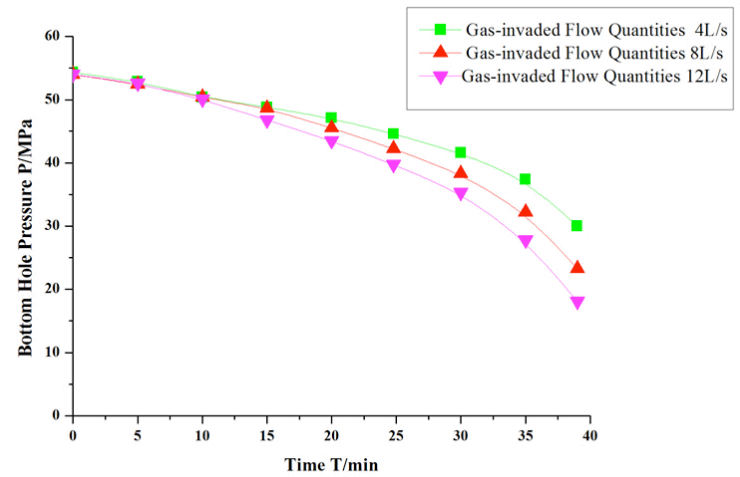

Fig. 10. Comparison Curves of Bottom Hole Pressure with Time under Different gas-invaded Flow Quantities

\subsection{Change of bottom hole pressure under different backpressures}

Fig. 11 shows the comparison curves of the change of bottom hole pressure with time under different backpressures. High control backpressure results in slow bottom hole pressure drop. Hence, this influence rule could be sufficiently used to regulate wellhead backpressure through the kill technology of a well to control wellbore pressure.

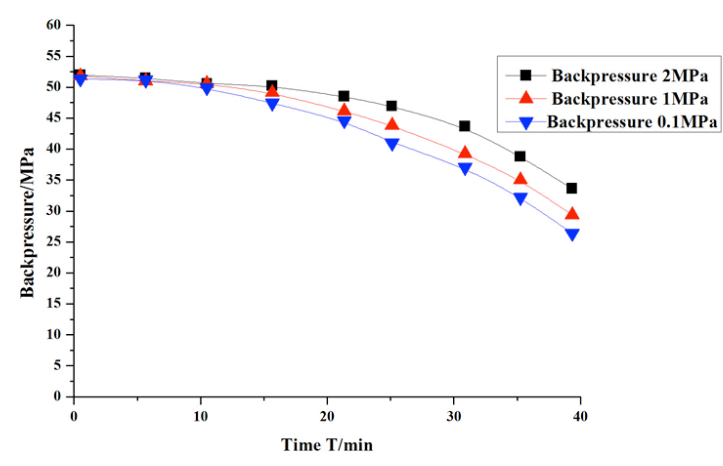

Fig. 11. Comparison Curves of Changes of the Bottom Hole Pressure with Time under Different Backpressures

\section{Conclusions}

A multiphase calculation model for a wellbore after the invasion of acid natural gas under high-temperature and high-pressure conditions was established in this study based on the changes of the acid natural gas solubility in the waterbased drilling fluid, and gas-liquid phase change of acid natural gas for the accurate prediction of multiphase flow regularity after the invasion of acid gas in the wellbore during an unbalanced drilling process. Subsequently, this model was used for the simulation analysis of the change rules of parameters, such as gas solubility in the water-based drilling fluid, annular gas phase volume fraction, mud pit increment, and bottom hole pressure drop during the acid gas cut period under high-temperature and high-pressure conditions. The following conclusions were drawn:

1) The solubility of $\mathrm{H}_{2} \mathrm{~S}$ in the wellbore changed gently with the lower part of the well, and its solubility rapidly decreased near the wellhead. Meanwhile, the density of $\mathrm{H}_{2} \mathrm{~S}$ sharply decreased near the wellhead, and the high $\mathrm{H}_{2} \mathrm{~S}$ content resulted in a significant change in the amplitude of density.

2) A high $\mathrm{H}_{2} \mathrm{~S}$ content during the gas invasion process results in a high $\mathrm{H}_{2} \mathrm{~S}$ content within the same overflow time, low bottom hole pressure drop, and shut-in casing pressure. When the backpressure at the wellhead increases, the bottom hole pressure correspondingly increases.

3) Under the same gas-invaded amount, a high $\mathrm{H}_{2} \mathrm{~S}$ content results in a small gaseous content during gas transportation toward the wellbore, high expansion times when the gas reach the wellhead, and increased mud pit increment. Under different gas-invaded velocities, a high gas-invaded velocity results in a low bottom hole pressure.

The established multiphase flow model could truly reflect the gas-liquid two-phase flow regularity inside the wellbore under high-temperature and high-pressure conditions through a comprehensive consideration on the influences of factors, such as phase change and solubility on the multiphase flow of a wellbore, thus providing the necessary theoretical basis for wellbore pressure control and overflow monitoring. The chemical reactions of acid natural gas and the water-based drilling fluid can be combined with this model in future study because the chemical actions of several components in the $\mathrm{H}_{2} \mathrm{~S}$ and drilling fluid were not considered. Moreover, appropriate correction can be made for a more accurate understanding of the multiphase flow regularity of a wellbore under the acid gas-invaded condition.

\section{Acknowledgements}

This work was supported by the "National Science and Technology Major Project" Integration Software System of Drilling Engineering (No.2016ZX05020-006).

This is an Open Access article distributed under the terms of the Creative Commons Attribution Licence

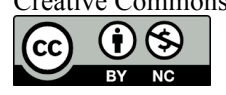

\section{References}

1. Wang, X., Feng, Q., Haynes, R. D., "Optimization of Well Placement and Production for Large-scale Mature Oil Fields". Journal of Engineering Science and Technology Review, 8(5), 2015, pp. 134-140.

2. Guo, B., Hareland, G., Rajtar, J., "Computer simulation predicts unfavorable mud rate and optimum air injection rate for aerated mud drilling”. SPE Drilling \& Completion, 25(05), 1996, pp. 6166.

3. Beggs, D. H., Brill, J. P., "A study of two-phase flow in inclined pipes". Journal of Petroleum technology, 11(02), 1973, pp. 607617.
4. Hasan, A. R., Kabir, C. S., "Two-Phase Flow in Vertical and Inclined Annuli". International Journal of Multiphase Flow, 18(2), 1992, pp.279-293.

5. Hasan, A. R., Kabir, C. S., Sayarpour, M., "Simplified two-phase flow modeling in wellbores". Journal of Petroleum Science and Engineering, 72(1), 2010, pp. 42-49.

6. Hasan, A. R., Kabir, C. S., "Modeling two-phase fluid and heat flows in geothermal wells". Journal of Petroleum Science and Engineering, 71(1), 2010, pp.77-86. 
7. Wiemann, D., Becker, D., "Calculation of flow fields in two and three-phase bubble columns considering mass transfer". Chemical engineering science, 60(22), 2005, pp. 6085-6093.

8. Pfleger, D., Mewes, D., "Modelling and simulation of the dynamic flow behaviour in a bubble column". Chemical engineering science, 56(4), 2001, pp. 1737-1747.

9 Anglart, H., "Dry patch formation in diabatic annular two-phase flows". Journal of Power Technologies, 94(5), 2015, pp. 85-95.

10. Xie, Y., Orsten, S., Oeters, F., "Behaviour of bubbles at gas blowing into liquid Wood's metal". ISIJ international, 32(1), 1992, pp. 6675.

11 Barshilia, H. C., Rajam, K. S., "Performance evaluation of reactive direct current unbalanced magnetron sputter deposited nanostructured TiN coated high-speed steel drill bits". Bulletin of Materials Science, 30(6), 2007, pp. 607-614.

12. Barnea, D., "Transition from annular flow and from dispersed bubble flow-unified models for the whole range of pipe inclinations". International journal of multiphase flow, 12(5), 1986, pp. $733-744$

13. Gatkowski, M. J., Buchner, T., Niewinski, G., "Development of a measurement and reconstruction system for determining the phase distribution in a two-phase flow vertical tube using Electrical Impedance Tomography". Journal of Power Technologies, 11(02), 2015, pp. 77-84

14. Sokolichin, A., Eigenberger, G., Lapin, A., "Dynamic numerical simulation of gas-liquid two-phase flows Euler/Euler versus Euler/Lagrange". Chemical engineering science, 52(4), 1997, pp. 611-626.

15. Sheldon, I. M., Lewis, G. S., LeBlanc, S., "Defining postpartum uterine disease in cattle". Theriogenology, 65(8), 2006, pp. 15161530 .
16. Auton, T. R., Hunt, J. C. R., Prud, Homme. M., "The force exerted on a body in inviscid unsteady non-uniform rotational flow". Journal of Fluid Mechanics, 19(7), 1988, pp. 241-257.

17. Hancock, L. L., "Application of a coupled euler-lagrange computer program to the structural response of an LMFBR". Nuclear Engineering and Design, 42(1), 1977, pp. 69-74.

18. Hancock, L. L., Stanbery, S. R., "Pressure dynamics in wells during gas kicks: Part 2-Component models and results". Journal of Petroleum Technology, 33(8), 1981, pp. 1367-1378.

19. Nickens, H. V., "A dynamic computer model of a kicking well". SPE Drilling Engineering, 2(2), 1987, pp. 159-173.

20. Jun, Fan., Tai, He. Shi., "Influences of low pressure and gas injection amount in unbalanced drilling on pressure inside the well". Journal of Southwest Petroleum Institute, 21(4), 1999, pp.50-52.

21. Hua, Shi., Jonathan, A., Holmes, Louis. J., "Drift-Flux Modeling of Two-Phase Flow in Wellbores". Society of Petroleum Engineers, 10 (1), 2005, pp. 24-32.

22. Hagedorn, A. R., Brown, K. E., "Experimental study of pressure gradients occurring during continuous two-phase flow in smalldiameter vertical conduits". Journal of Petroleum Technology, 17(4), 1965, pp. 475-484.

23. Duan, Z., Mao, S., "A thermodynamic model for calculating methane solubility . density and gas phase composition of methane-bearing aqueous fluids from 273 to $523 \mathrm{~K}$ and from 1 to2000bar". Geochimica et Cosmochimica Acta, 70(13), 2006, pp. 3369-3386.

24. Duan, Z., Sun, R., Liu, R., "Accurate thermodynamic model for the calculation of $\mathrm{H}_{2} \mathrm{~S}$ solubility in pure water and brines". Energy \& Fuels, 21(4), 2007, pp. 2056-2065.

25. Duan, Z., Sun, R., "An improved model calculating $\mathrm{CO}_{2}$ solubility in pure water and aqueous $\mathrm{NaCl}$ solutions from 273 to $533 \mathrm{~K}$ and from 0 to 2000 bar". Chemical Geology, 193(3), 2003, pp. 257-271. 